\title{
Retraction:
}

(Widyowijatnoko, A., \& Aditra, R. F. (2018). Application of bamboo radial compression joint for tension and knock-down structures. Indonesian Journal of Science and Technology, 3(1), 40-46.)

\section{Application of Bamboo Radial Compression Joint for Tension and Knock-Down Structures}

Andry Widyowijatnoko, Rakhmat Fitranto Aditra

School of Architecture, Planning and Policy Development, Institut Teknologi Bandung, 40132, Indonesia

Correspondence: E-mail: rakhmat.aditra@gmail.com

Available online: 09 April 2018

This article has been retracted by Indonesian Journal of Science and Technology Editorial team, following clear correspondence and confirmation with authors.

The paper is retracted from 30 May 2021. 


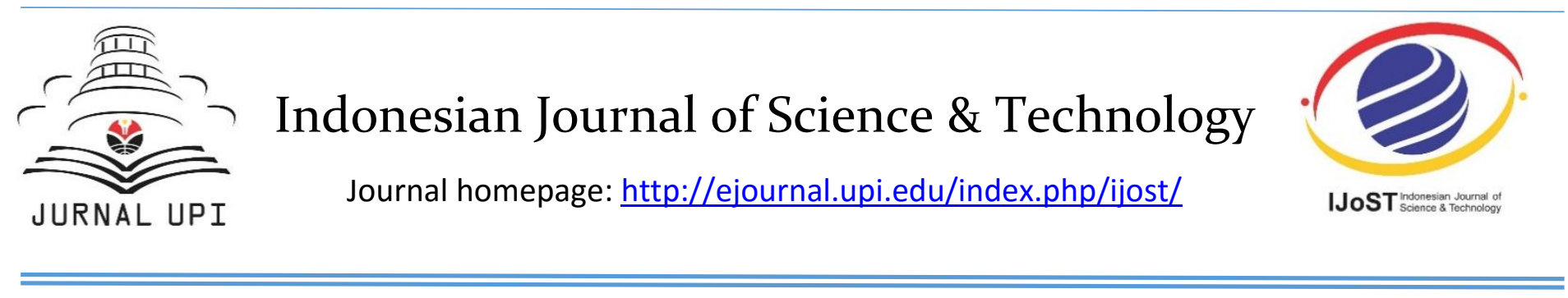

\title{
Application of Bamboo Radial Compression Joint for Tension and Knock-Down Structures
}

\author{
Andry Widyowijatnoko ${ }^{1}$, Rakhmat Fitranto Aditra ${ }^{1 *}$ \\ ${ }^{1}$ School of Architecture, Planning and Policy Development, Institut Teknologi Bandung, 401 2, ndonésia \\ Correspondence: E-mail: rakhmat.aditra@gmail.com
}

\begin{abstract}
A B STRACTS
Bamboo applications become popular recently by the community due to the rise of environmental awareness, including for post-disaster building. Two aspects of post-disaster buile ings were considered: i.e. its performance and its recyclabil ity. This research explore ability of bamboo as tensile st to ture, and also as knock-down structure. Bamboo ra an conpression (barcom) connection was explored by thes asfects. Barcom joint is one of the solutions to be effectiveny used for gaining the tensile strength of bamboo by converting tensile load parallel to fiber into radial compressior purpendicular to fiber. Barcom joint was tested to acquire s sad capacity and its future improvement. The load tes $\mathrm{s}$ owed that the barcom connection could reach ur to $1 . \mathrm{kN}$. To improve this capacity, either better wire or $n$ cialwasher design could be proposed. The adaption in previcus built structure (i.e. Three Mountain Building in Ser ang island, Bali and knock-down bamboo geodesic dor 10 . (olombia) was used as a casestudy. In the const uol of Three Mountain Building, barcom joint was ufed twang the bamboo rafters and acts as tension-like neme Meanwhile, the use of barcom joint in Colombia y anded to connect the bamboo with the steel bowl con ne tor which could be dismantled and reused again many CI re.c 2018 Tim Pengembang Jurnal UPI
\end{abstract}

\section{NTRODUCTION}

Bamboo pole construction was one of the most used construction types. Its availability also made bamboo frequently used as a post disaster building (Schilderman, 2004), such as after the earthquake in West
Java 2009 (International Federation of Red Cross and Red Crescent Societies., 2011).

Two aspects of the post-disaster building were its performance and its recyclability. (International Federation of Red Cross and Red Crescent Societies., 2011). Thus, this 
research explores ability of bamboo as tensile structure to withstand uplift, and also as knock-down structure.

New tensile connection, radial compression connection, will be explored Since it is important for construction uses (Nurprasetio et al., 2017). Improvement was tested, and the application in the build structure was elaborated.

The use of bamboo radial compression connection for knock-down also was explored. The need of knock-down structure for post-disaster building was discussed and the application in the built structure was elaborated.

\section{METHOD}

\subsection{Tensile Structure for Cyclone Prone Area.}

Tension member is a term for member of linear structure that only experience tensi force (Awan et al., 2017). Tension memor could be present in trusses struature, tensegrity structure, or cable en ion structure. Tension member dos n t require high width to length rasio sin $\mathrm{e}$ would not experience buckling (Nurpras tio et al., 2017).

Bamboo is a lighty ight material. While this is good for ent ke, it is prone to cyclone. Direct wing force could cause the structure to be blown away. Suction also could be c ea by different pressure between dorr and outdoor. Even if the cladding an well attached, if the whole structar - light, the building could be ve tu nd d (see http://nidm.gov.in P a afety/flood/link2.pdf). Thus, it is in portant for bamboo structure to have construction that could withstand wind force by transferring the tension force to the ground.

Traditional bamboo connection usually rely on natural material such as rattan, cocopalm or bast for lashing and also bamboo or wood dowel. Meanwhile, the modern connection usually based on bolted joint with or without concrete filling (Disén \& Clouston, 2013).

One particular connection design was Bamboo radial compression conr pction. It uses force transferring mode of "Tran ferring radial compression to the cen er of the pole through shear and circlmi re $\nu^{+}$al stress perpendicular to the fibers Th s category of load transfer was rardy exprored. Bamboo radial compression conne ton was invented to utilize the roundress of bamboo and the hardest outer skin bamboo (Zhuo-ping, 2004).

Ban ho ralal compression connection could reac w to $38.07 \mathrm{kN}$. One of the crucial aspeas of the connection is the washer. wicer yasher is needed to avoid slipping. Non sabchapter will explore the splitting beh vior of sample with new washer design.

\subsection{Tensile Test.}

Gigantochloa Apus is used for the samples. Bamboo radial compression connection will be assembled to the each end of three samples. Bamboo radial compression connection will be assembled to the each end of three samples. Thus, total of six joint of bamboo radial compression connection will be tested. Each of three sample will be tested until one of the end failed. Thus, only the failed end that could reach its ultimate load.

Figure 1 shows the connection design. It used M10 threaded rod class 8.8 DIN 975/976 with minimum tensile strength of $46.4 \mathrm{kN}, \mathrm{M} 4$ 6x7 wire with a minimum breaking force of 9.4 $\mathrm{kN}$, end washer made from $10 \times 10 \times 2 \mathrm{~cm}$ thick OSB, $12 \mathrm{~mm}$ Stainless Steel Lifting Eye Nut DIN 582 with maximum work load of $340 \mathrm{~kg}$. Special washer was made from $1 \mathrm{~mm}$ thick mild steel plate formed into washer and two $2 \mathrm{~mm}$ thick mild steel plate welded as reinforcement (Figure 2). 


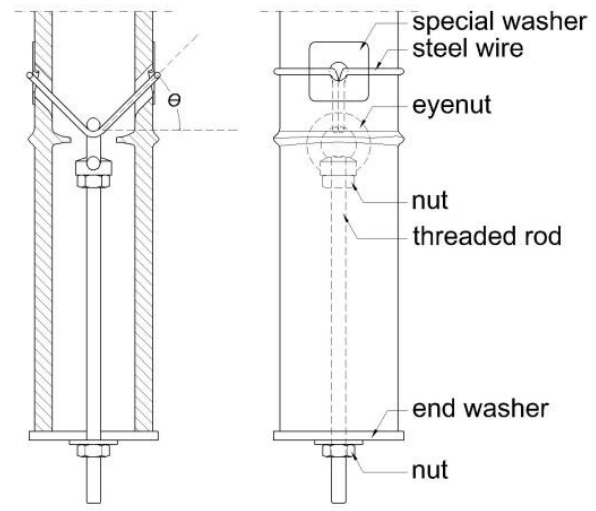

Figure 1. Bamboo radial compression connection

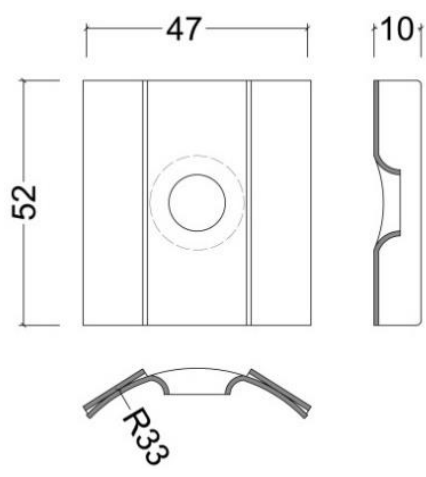

Figure 2. New special wash

The test was set as shown in $\mathrm{A}$ sure 3. Speed of the displacement of the was $0.6 \mathrm{~mm}$ per second. The displacement of reach joint was retrieved by dial log Th 1 itimate load capacity, failure mode, and loa 4 -andacement graph was recorded.

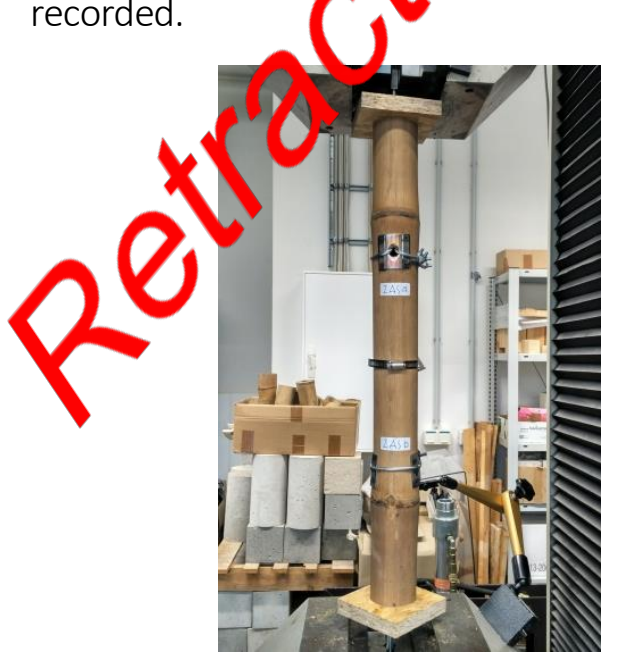

Figure 3. Test setting

\subsubsection{Ultimate Load Prediction.}

As the previous research showed, bamboo radial compression connection would likely to fail in the wire. The ultimate load of the connection could be predicted as

$$
\begin{aligned}
& F_{u t|| w}=\Sigma f_{w}{ }^{*} \sin \theta \\
& F_{u t|| w} \text { was the ultimate }
\end{aligned}
$$
connection if the failure va in wire. $\Sigma f_{w}$ was the total of load capacity of the wire that pulled by the eyenut. Since the were two wires passing through the ey nut, thus,

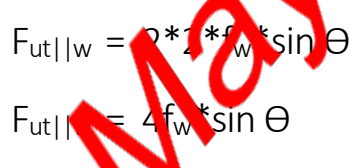

he the $\theta$ was the slope of the wire inside bar boc (Figure 1). Since, it was assumed that there ws no radial deformation in the tested sam le during the test, the theta $\theta$ could be assumed as $45^{\circ}$.

With the load capacity of the wire was 9.4 $\mathrm{kN}$, from the equation 2 , it could be assume that the ultimate load capacity of the connection

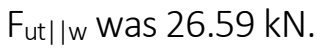

\section{RESULTS}

\subsection{Ultimate load capacity}

Table 1 concludes the result of the tensile test. The test shows that average of the ultimate tensile capacity of the samples were $20.62 \mathrm{kN}$, which was $22 \%$, which is lower than the predicted load capacity.

Table 1. Experimental Test Result

\begin{tabular}{clcc}
\hline Sample & Joint & $\begin{array}{c}\text { Displacement } \\
\mathrm{mm}\end{array}$ & $\begin{array}{c}\text { Max-load } \\
\mathrm{kN}\end{array}$ \\
\hline \multirow{2}{*}{ 1AS } & Upper & 16.57 & 21.19 \\
\cline { 2 - 4 } & Lower & 17.43 & - \\
\hline \multirow{2}{*}{$2 \mathrm{AS}$} & Upper & 22.36 & - \\
\cline { 2 - 4 } & Lower & 22.5 & 21.61 \\
\hline \multirow{2}{*}{$3 \mathrm{AS}$} & Upper & 16.77 & - \\
\cline { 2 - 4 } & Lower & 14.97 & 19.07 \\
\hline \multicolumn{2}{c}{ Average } & 18.43 & 20.62 \\
\hline
\end{tabular}




\subsection{Deformation}

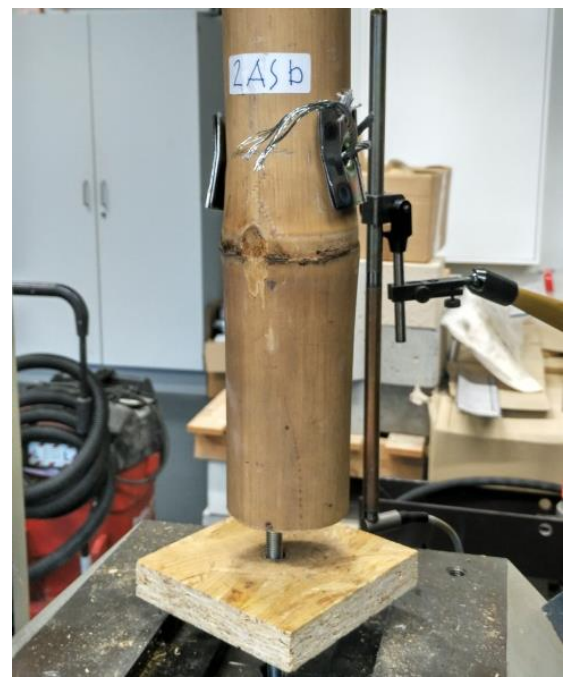

Figure 4. Failure in wire

All of the samples had no significant sign of diametrical compression. The washer also did not show significant deformation if compared with the previous research (Figure 4). All of th wire failure happened near or on the was eventhough there is no sign of wire cut by the washer.

\section{DISCUSSION}

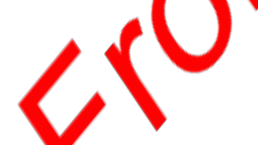

From the result, it showed th the washer had not slide into the ban boo and had no significant deformation. Bu th. wire failure on the washer might sugg s the rough and thick edge of the washer th t $\mathrm{a}$ sed the wire to bend to large that decrease capacity around that area. Smoothe tho er but stronger material of washer mightir cease the performance of the connectin.

\subsection{A pricacion As Tensile Structure}

one of the applications of Bamboo radial c mpression Connection in for tension member was in the refurbishment of Three Mountain Building in Pulau Serangan (Figure 5).

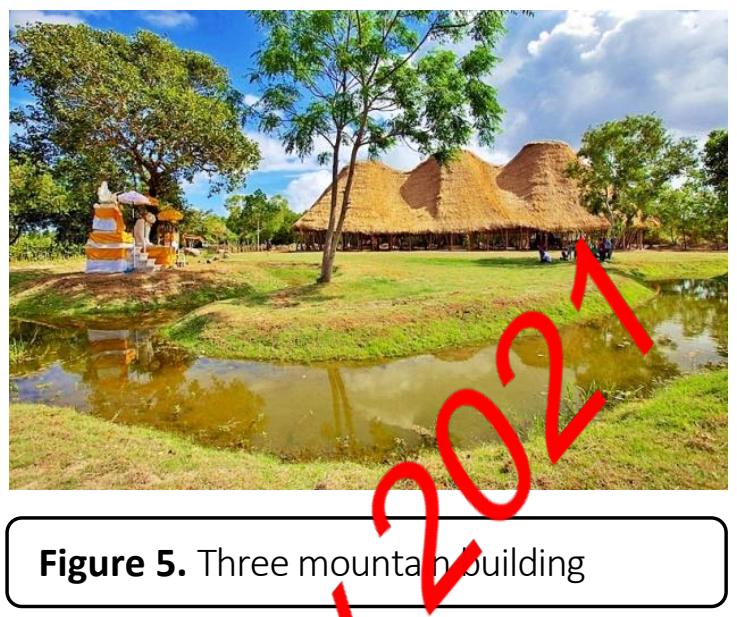

Three Mountan Building was the refurbishme the recation of the older building in UAd the building has a flexible structura s, then which relies on three towers which then pnnected with the ground via series of ban boo rafters that acted as tension $m$ mer. At the previous location, the building was omplained to be unstable and unable to be used. This was due to weak connection between the tower and the rafters. The the building was relocated to Pulau Serangan. For the stability improvement, bamboo radial compression connection was used at the second location (Figures 6 and 7).

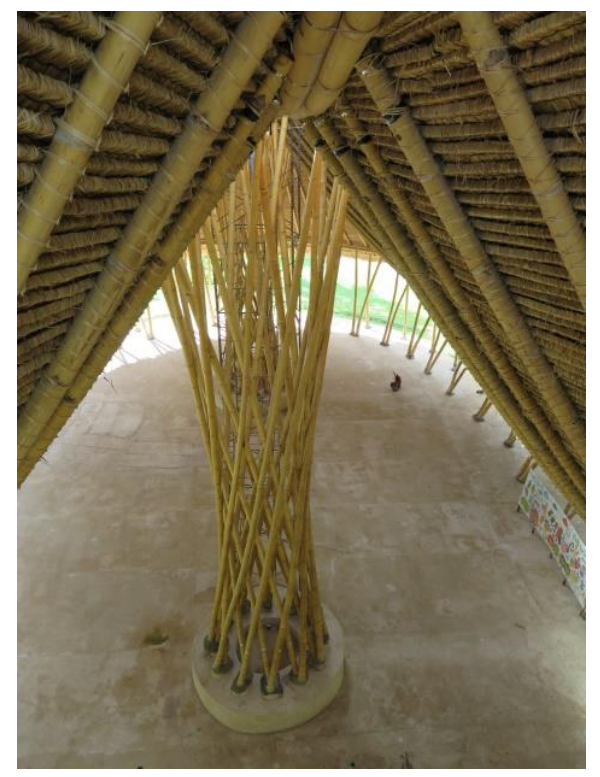

Figure 6. Interior of Three Mountain Building (Widyowijatnoko, 2016) 


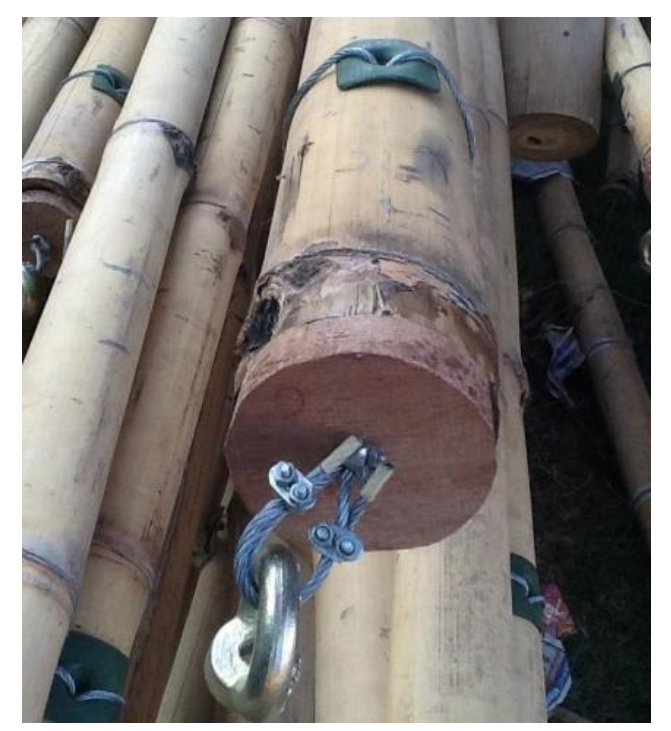

Figure 7. Bamboo radial compression connection (Widyowijatnoko, 2016)

The bamboo radial compression connections were used to connect the laminated bamboo ring which tied the tower with the bamboo rafters. To simplify the connection, the bamboo radial compression directly used vir instead of threaded steel bar.

\subsection{Knock-Down Construction for rosus- ter Building}

Knock-down construct n wa defined as construction where the copponents were manufactured in off-site son bled onsite, and could be disassembled to reused in other site. Bamboo structure alivy used as temporary material. Since the conventional bamboo construction ing veu dove tail, drilling, grouting, and notch u ed bamboo structure usually discardeu (P ramita et al., 2016). Many of socalled nouk-down bamboo structure are ctl al o efabricated structure.

As it is needed for post disaster structure to be assembled quickly and reused, knock-down construction was important for a post disaster building. As mentioned by (Johnson et al., 2006; Quarantelli, 1994), there are four post disaster housing phase; (1) emergency shelter (within hours),(2) temporary shelter (within days), (3) temporary housing (within weeks), and (4) permanent housing (within years). As mentioned by (International Federation of Red Cross and Red Crescent Societies, 2011), transitional shelter should be designed so that it could be relocated or the material used could be re-used.

\subsection{Application as Knock-down a ucture}

Bamboo radial compresion sonnection was designed to be easy to const uut. By having steel material as the en $c$ nnctor, instead of bamboo itself, it could be fy ther designed as knock-down system. The material for the connection is almo basy to acquire in any building stor u lib otl er steel-ended bamboo connection w i ch cocially built for bamboo pole construci the material required were such as threaded s eel rod, steel or wood plate as wa her, steel wire, and wire clip. The only com on meed to be specialy made is the spec al washer.

In the next subchapters, the example of the application of the bamboo radial compression connection for knock-down structure will be described.

The example of the knock-down construction was a geodesic dome in Columbia. It was based on icosahedron shape with bamboo length of 2 meters.

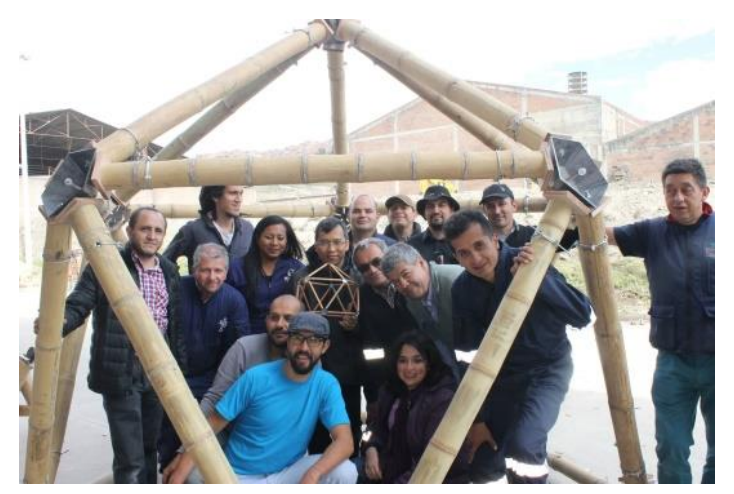

Figure 8. Geodome structure in Columbia

The idea of the construction is in the connection of the threaded steel rod and the steel bowl. The steel bowls were identical, truncated pentagonal pyramid. Each faces of the 
bowl has slit in which the threaded rod of the member could be inserted and secured by nuts. The assembling process took only few hours.

The whole structure could be relocated by simply deattached the member and the bowl connection. Other than that, in case of rural area with its own bamboo supply, the bamboo radial compression joint components and the bowl connection could be re-used to make the same structure.

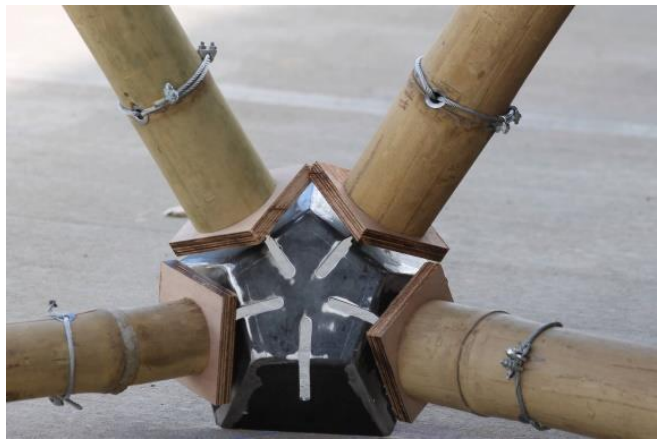

Figure 9. Knock-down connection

Larger span could be made by increa ing the bamboo length, or adding more seg ne, t the icosahedron, creating smot er wo shape. Example of this cor rigration was created in World Bamboo Fes val 2015 in Damyang, South Korea. (Kim al., 2015)

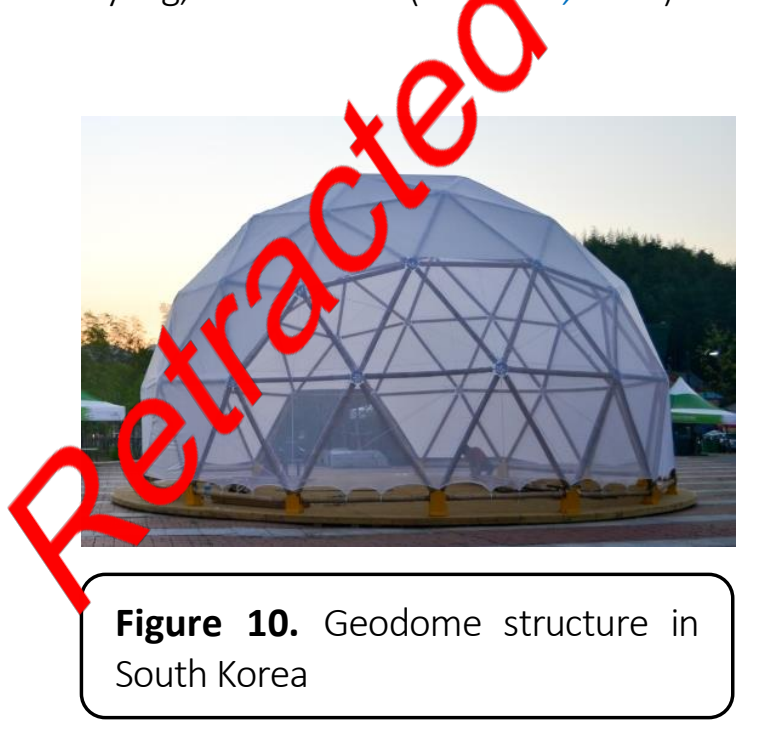

The 10 meter geodesic dome structure was built with 3 variation of connection and 3 variation of struts. Total of the connections were 61 components, and 165 for the struts. This dome was assembled in 2 days

\section{CONCLUSION}

Bamboo pole construction wa suitable construction for post-disas er a ui,ding. For a better application, it nee is p n rove its tensile load transferring capability, aryd its recyclability. Bamboo radial comprssior connection had the advantage in both sects. The most simple bamboo radial cenpression connection with improvemen in sréciál washer design could withstan wo to $21.61 \mathrm{kN}$ of tensile load. To improve $t$ is lapacity, better wire or special wa he design could be proposed. With its steeland oin, availability of the component in the man et, also the fast assembling process made tho bamboo radial compression connection suitable for knock-down structure. The shape of the structure could be adjusted by using different bowl connection, which could always be reused.

\section{ACKNOWLEDGMENTS}

We would like to thank the Department of Civil Engineering of Erfurt University of Applied Science for its cooperation and contribution for this joint research. We are also grateful for Politeknik Manufaktur Bandung (Manufacture Polytechnic) and the participant and the committee of IV Simposio Internacional del Bambú y la Guadua for their cooperation in the fabrication process of the Bamboo Geodesic Dome.

\section{AUTHORS' NOTE}

The author(s) declare(s) that there is no conflict of interest regarding the publication of this article. Authors confirmed that the data and the paper are free of plagiarism. 


\section{REFERENCES}

Awan, M. M. S., Soroushian, P., Ali, A., \& Awan, M. Y. S. (2017). Use of Carbon Nano-Fibers in Cementitious Mortar. Indonesian Journal of Science and Technology, 2(2), 134-151.

Disén, K., \& Clouston, P. L. (2013). Building with bamboo: a review of Culm opnnection technology. Journal of Green Building, 8(4), 83-93.

http://nidm.gov.in/PDF/safety/flood/link2.pdf. Retrieved on December 2017

International Federation of Red Cross and Red Crescent Societies. (2011, Agu stus 4). PostDisaster Shelter: Ten Designs. Geneva, Switzerland.

Johnson, C., Lizarralde, G., \& Davidson, C. H. (2006). A systems view of emporary housing projects in post-disaster reconstruction. Construction Manacement and Economics, 24(4), 367-378.

Kim, J. H., Cho, S. W., Park, D. J., Lee, K. H., Choi, C. H. \& Wo, V. S. (2015). Local Festival Marketing and Application Plan for Agricultural Mdyces by Utilizing Big Data from Online Shopping Mall. Proceedings of the 2015 Int nnational Conference on Big Data Applications and Services, 2015, 233-236.

Nurprasetio, I. P., Budiman, B. A., \& Triawan, F. (2014) Fullure Investigation of Plastic Shredding Machine's Flange Coupling Based on Mechanital Analysis. Indonesian Journal of Science and Technology, 2(2), 124-133.

Paramita, B., Kamilia, I., Nurhidayat, M. I. Otktaviyane, R. (2016). Optimization of Design and Planing VHS Building Using Ch On lux. Indonesian Journal of Science and Technology, 1(2), 170-184.

Quarantelli, E. L. (1994). Patte of shelter and housing in US disasters. Disaster Prevention and Management, 43-5.

Schilderman, T. (2004). Adapt hg traditional shelter for disaster mitigation and reconstruction: experiences w th formmunity-based approaches. Building Research \& Information, 32(5), 414-4

Widyowijatnoko, A. 2016). Development of Bamboo Radial Compression Joint. IV Simposio Internac nar del Bambú y la Guadua.

Zhuo-pil, H.A. O. (2004). Mechanical Behavior of Bamboo with Large Deformation II. The pe

DOI: http://dx.doi.org/10.17509/ijost.v3i1.10807 p- ISSN 2528-1410 e- ISSN 2527-8045 